\title{
Comunicação
}

[Communication]

\section{Efeitos do horário de postura de matrizes pesadas sobre o rendimento de incubação}

[Effects of oviposition time from broiler breeders on the incubation yield]

\author{
V.M. Barbosa ${ }^{1}$, J.S.R. Rocha ${ }^{2}$, M.A. Pompeu ${ }^{2}$, M.N.S. Fernandes ${ }^{2}$, A.C. Machado ${ }^{2}$, \\ C.E. Cunha ${ }^{2}$, P.C. Cardeal ${ }^{2}$, L.E.A. Ruiz ${ }^{3}$, L.J.C. Lara $^{4}$, N.C. Baião ${ }^{4}$
}

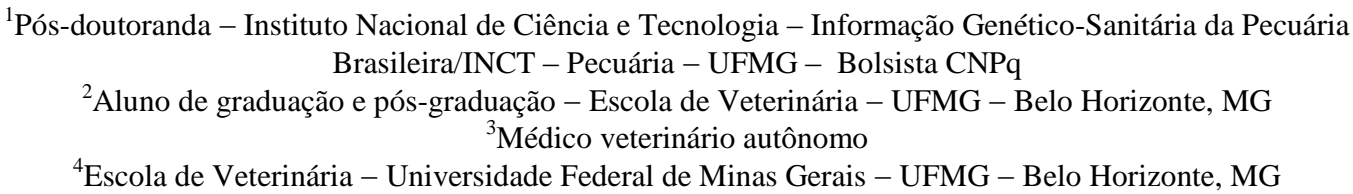

O ovário de uma ave em condições normais apresenta a chamada "hierarquia folicular", caracterizada por vários estágios de desenvolvimento que envolvem cerca de 10 a 12 folículos, liberados consecutivamente. As sequências são separadas por um período de pausa, que dura aproximadamente 40 horas. Desta forma, o ciclo de postura ocorre em dias sucessivos, seguidos de uma interrupção (pausa de postura) e um recomeço (North, 1984; Barbosa e Baião, 2011). O primeiro ovo de cada sequência é usualmente posto mais cedo, e os subsequentes são postos um pouco mais tarde nos dias seguintes. Portanto, grandes proporções dos ovos coletados no período da manhã são da primeira sequência (Choi et al.,1981).

De acordo com Robinson et al. (1991) e Novo et al. (1997), o peso do ovo da primeira sequência de matrizes pesadas (primeira coleta do dia) é maior do que os ovos em posições posteriores. Fasenko et al. (1992) relataram que o folículo maduro do primeiro ovo da sequência permanece no ovário e no oviduto por mais tempo que os folículos subsequentes. Segundo estes autores, os tempos excedentes influenciam a fertilização, a viabilidade e o estágio de desenvolvimento embrionário no momento da postura. Entretanto, Zakaria et al. (2005) e Zakaria et al. (2009) não observaram efeitos dos horários (manhã, meiodia e à tarde) de coleta dos ovos sobre a perda de peso do ovo durante a incubação, a fertilidade, a eclodibilidade e a mortalidade embrionária.
O objetivo deste estudo foi determinar os efeitos do horário da postura, que representa diferentes posições dos folículos em uma sequência, sobre o rendimento de incubação. Foram utilizados, no mesmo dia de produção, 19.820 ovos de um lote de matrizes pesadas Cobb®, com idade de 46 semanas. Às sete horas da manhã, realizou-se a retirada dos ovos que se encontravam nos galpões, com o objetivo de excluir ovos postos no dia anterior. Os ovos postos subsequentemente foram classificados de acordo com os horários de postura (correspondentes aos horários de coletas), de 8h30min, 10h30min, $12 \mathrm{~h} 30 \mathrm{~min}, 14 \mathrm{~h} 30 \mathrm{~min}$ e $16 \mathrm{~h} 30 \mathrm{~min}$, que representaram os tratamentos, denominados primeira, segunda, terceira, quarta e quinta coletas, respectivamente.

Os ovos destinados à incubação foram fumigados na granja e encaminhados para o incubatório. Após três dias de armazenamento em temperatura média de $19,3^{\circ} \mathrm{C}$ e umidade relativa do ar (UR) de $84,0 \%$, realizou-se a seleção dos ovos, sendo eliminados os sujos, trincados, quebrados, pequenos, com duas gemas e deformados. Os ovos foram colocados em bandejas de incubação, com capacidade para 96 ovos cada, totalizando 36 bandejas e 3.964 ovos por tratamento. O pré-aquecimento dos ovos ocorreu 10 horas antes do início da incubação, em temperatura média de $28,5^{\circ} \mathrm{C}$ e UR de $75,2 \%$. Antes da entrada dos ovos nas incubadoras, todas as bandejas foram pesadas individualmente. 
A incubação foi realizada no mesmo momento para todos os tratamentos, em uma incubadora modelo Casp® $\mathrm{CMg}$ 125E de estágio múltiplo, que teve seu termostato regulado para manter constante a temperatura do bulbo seco em $37,4^{\circ} \mathrm{C}$ $\left(99,3^{\circ} \mathrm{F}\right)$ e UR de $62 \%$. As bandejas foram dispostas ao acaso na máquina de incubação. No $12^{\circ}$ dia de incubação, foi realizada a ovoscopia e os ovos claros foram retirados para identificação dos inférteis ou dos embriões mortos. Os dados foram registrados para, posteriormente, serem incluídos na análise final de mortalidade embrionária e fertilidade. Com 19 dias de incubação, os ovos foram transferidos para a sala de eclosão, quando todas as bandejas foram novamente pesadas. A análise de perda de peso dos ovos durante o período de incubação foi determinada por pesagem individual de todas as bandejas de cada tratamento, antes de os ovos serem colocados na incubadora e no momento em que foram transferidos para os nascedouros. O percentual de perda de peso dos ovos foi obtido pela seguinte fórmula:

perda de peso $(\%)=($ peso ovos na incubação - peso de ovos na transferência $x$ 100)

peso de ovos na incubação

Após a pesagem, os ovos foram transferidos para bandejas de eclosão, as quais foram dispostas ao acaso em um nascedouro modelo Casp® G21 E, com capacidade para 20.736 ovos e com termostato programado para manter a temperatura do bulbo seco em $36,6^{\circ} \mathrm{C}\left(98^{\circ} \mathrm{F}\right)$ e UR de $65 \%$. A retirada dos pintos dos nascedouros ocorreu com 504 horas (21 dias) de incubação e o número de pintos nascidos e ovos não eclodidos de cada bandeja foi registrado. A taxa de eclosão em relação ao total de ovos incubados, expressa em porcentagem, foi calculada dividindo-se o número total de pintos nascidos pelo número total de ovos incubados e multiplicando-se por 100 . Os pintos foram pesados de acordo com os tratamentos e as repetições.

O embriodiagnóstico foi realizado ao final do período de incubação em todos os ovos não eclodidos, conforme a seguinte classificação: ovos inférteis; ovos com embriões que morreram no início da incubação (zero a sete dias); ovos com embriões que morreram entre oito e 18 dias de incubação; ovos com embriões que morreram entre 19 e 21 dias de incubação e ovos bicados (pintos que não conseguiram eclodir, vivos ou mortos). Após essa análise, os dados de mortalidade inicial e os ovos inférteis obtidos aos 12 dias na ovoscopia foram somados, sendo, então, calculados o percentual de mortalidade embrionária em relação aos ovos férteis incubados e o percentual de fertilidade em relação ao total de ovos incubados.

O delineamento experimental utilizado foi inteiramente ao acaso, com cinco tratamentos e
36 repetições cada, sendo a bandeja com 96 ovos considerada a repetição. Os dados normais e homogêneos foram submetidos às análises de variância, e as médias comparadas pelo teste de Tukey (Sampaio, 2002). As médias das respostas não normais e não homogêneas foram comparadas pelo teste de Kruskal-Wallis, utilizando-se o programa SAEG, versão 9.1 (Sistema..., 2005).

Conforme mostram os dados da Tab. 1, o peso dos ovos foi significativamente maior $(\mathrm{P} \leq 0,05)$ na primeira coleta, realizada às $08 \mathrm{~h} 30 \mathrm{~min}$, quando comparada aos outros horários de coleta, que foram semelhantes entre si. Como o peso do pinto é proporcional ao peso do ovo, os pintos oriundos de ovos da primeira coleta apresentaram-se mais pesados $(\mathrm{P} \leq 0,05)$ que os pintos provenientes da segunda à quinta coleta. Esses resultados corroboram os encontrados por Robinson et al. (1991) e Novo et al. (1997), que trabalharam com matrizes pesadas Indian River ${ }^{\circledR}$ e Cobb 500®, respectivamente, e iniciaram a primeira coleta entre oito e nove horas da manhã. A menor perda de peso dos ovos durante a incubação foi identificada na quinta coleta, e a maior perda de peso ocorreu na segunda e quarta coletas $(\mathrm{P} \leq 0,05)$. A primeira e a terceira coletas tiveram valores semelhantes entre si $(\mathrm{P}>0,05)$ e intermediários aos outros tratamentos. Por outro lado, com relação à perda de peso dos ovos durante a incubação, Zacaria et al. (2009) não encontraram diferenças significativas entre os tratamentos representados pelos horários de coletas dos ovos. Apesar de essa variável não ter sido semelhante entre os tratamentos neste experimento, seus valores foram próximos e 
dentro da faixa aceitável, que é de 11 a $12 \%$, segundo Tullett (1990). A eclodibilidade não foi afetada pelo horário de coleta $(\mathrm{p}>0,05)$, o que corrobora os dados obtidos por Zacaria et al. (2005) e Zacaria et al. (2009).

Não houve efeito $(\mathrm{P}>0,05)$ dos horários de coleta dos ovos sobre o percentual de ovos inférteis e as mortalidades inicial, média e final (Tab. 2). Esses resultados foram semelhantes aos encontrados por Fasenko et al. (1992), Novo et al. (1997), Zacaria et al. (2005) e Zacaria et al. (2009).

Conclui-se que o horário da postura de matrizes pesadas influencia o peso dos ovos e o peso dos pintos, mas não afeta a eclodibilidade, a fertilidade e o desenvolvimento embrionário.

Tabela 1. Peso dos ovos, peso dos pintos, perda de peso durante a incubação e eclodibilidade, de acordo com os horários de coleta dos ovos

\begin{tabular}{ccccc}
\hline Coleta/Horário & $\begin{array}{c}\text { Peso do ovo } \\
(\mathrm{g})\end{array}$ & $\begin{array}{c}\text { Perda de peso do } \\
\text { ovo }(\%)\end{array}$ & $\begin{array}{c}\text { Peso dos pintos } \\
(\mathrm{g})\end{array}$ & $\begin{array}{c}\text { Eclodibilidade } \\
(\%)\end{array}$ \\
\hline Primeira - 8h30min & $62,3 \mathrm{a}$ & $11,5 \mathrm{ab}$ & $41,7 \mathrm{a}$ & 87,4 \\
Segunda - 10h30min & $60,8 \mathrm{bc}$ & $11,2 \mathrm{~b}$ & $40,8 \mathrm{~b}$ & 86,9 \\
Terceira - 12h30min & $60,7 \mathrm{c}$ & $11,3 \mathrm{ab}$ & $40,6 \mathrm{~b}$ & 88,1 \\
Quarta - 14h30min & $60,9 \mathrm{bc}$ & $11,2 \mathrm{~b}$ & $40,2 \mathrm{~b}$ & 87,5 \\
Quinta - 16h30min & $61,1 \mathrm{~b}$ & $11,6 \mathrm{a}$ & $40,6 \mathrm{~b}$ & 87,4 \\
C.V (\%) & 0,93 & 4,27 & 2,45 & 4,51 \\
\hline
\end{tabular}

Médias seguidas de letras distintas na coluna são diferentes pelo teste de Tukey $(\mathrm{P} \leq 0,05)$.

Tabela 2. Percentual de ovos inférteis e mortalidade embrionária, de acordo com os horários de coleta dos ovos

\begin{tabular}{lcccc}
\hline Coleta / Horário & $\begin{array}{c}\text { Ovos } \\
\text { inférteis }\end{array}$ & $\begin{array}{c}\text { Mortalidade } \\
\text { inicial (0-7d) }\end{array}$ & $\begin{array}{c}\text { Mortalidade média } \\
(8-18 d)\end{array}$ & $\begin{array}{c}\text { Mortalidade } \\
\text { final (19-21d) }\end{array}$ \\
\hline Primeira - 8h30min & 4,22 & 4,74 & 0,38 & 2,98 \\
Segunda - 10h30min & 3,73 & 4,75 & 0,52 & 3,86 \\
Terceira - 12h30min & 3,90 & 4,43 & 0,29 & 3,12 \\
Quarta - 14h30min & 3,82 & 5,56 & 0,35 & 2,69 \\
Quinta - 16h30min & 4,05 & 4,03 & 0,51 & 3,41 \\
\hline
\end{tabular}

Médias na coluna são semelhantes pelo teste de Kruskal-Wallis $(\mathrm{P}>0,05)$.

\begin{abstract}
The effects of oviposition time, which represents different positions of the follicles in a sequence of posture, were studied on egg weight, chick weight, egg weight loss during incubation, hatchability, embryo mortality and infertility. A total of 19, 820 eggs, layed on the same day, from Cobb ${ }^{\circledR}$ broiler breeders aging 46-week-old were used. The eggs were classified according to the oviposition time posture (corresponding to the time of collection) from 8:30 am, 10:30 am, 12:30 pm, 14:30 pm and 16:30 $\mathrm{pm}$, which represented the folowing treatments: $1 \mathrm{st}, 2 \mathrm{nd}, 3 \mathrm{rd}$, 4th and 5 th collects, respectively. The experimental design was completely randomized with five treatments and 36 repetitions, and each tray of 96 eggs was considered a repetition. The normal and homogeneous data were submitted to analysis of variance and means compared by Tukey test. The non-normal and non-homogeneous averages were compared by Kruskal-Wallis test. It is concluded that the time of egg laying has influence on egg weight and chick weight, but does not affect hatchability, fertility and embryonic development.
\end{abstract}

Keywords: broiler breeders, embryo development, incubation, time of laying 


\section{AGRADECIMENTOS}

Ao CNPq, à Granja Pif-Paf e ao INCT-Pecuária.

\section{REFERÊNCIAS}

BARBOSA, V.M.; BAIÃO, N.C. Formação e estrutura do ovo incubável. In: BARBOSA, V.M. (Ed) Fisiologia da incubação e desenvolvimento embrionário. Belo Horizonte: FEPMVZ, 2011. p.01-09.

CHOI, J.H.; MILES, R.D.; ARAFA, A.S. et al. The influence of oviposition time on egg weight, shell quality and blood phosphorus. Poult. Sci., v.60, p.824-828, 1981.

FASENKO, G.M.; HARDIN, R.T.; ROBINSON, F.E. Relationship of hen age and egg sequence position with fertility, hatchability, viability and preincubation embryonic development in broiler breeders. Poult. Sci., v.71, p.1374-1383, 1992.

NORTH, M.O. Commercial Chicken Production Manual. (3 Ed). Oceanside: THE AVI PUBLISHING COMPANY, 1984. 710p.

NOVO, R.P.; GAMA, L.T.; SOARES, M.C. Effects of oviposition time, hen age, and extra dietary calcium on egg characteristics and hatchability. J. Appl. Poult. Res., v.6, p.335-343, 1997.
ROBINSON, F.E.; HARDIN, R.T.; ROBINSON, N.A. et al. The influence of egg sequence position on fertility, embryo viability and embryo weight in broiler breeders. Poult. Sci., v.70, p.760-765, 1991.

SAMPAIO, I.B.M. Estatística aplicada à experimentação animal. 2. Ed. Belo Horizonte: FEPMVZ, 2002. 265 p.

SISTEMA de análises estatísticas e genéticas. Versão 9.1. Viçosa: UFV, 2005.

TULLETT, S.G. Science and the art of incubation. Poult. Sci., v.69, p.1-15, 1990.

ZAKARIA, A.H.; PLUMSTEAD, P.W.; ROMERO-SANCHEZ, H. et al. Oviposition pattern, egg weight, fertility and hatchability of young and broiler breeders. Poult. Sci., v.84, p.1505-1509, 2005.

ZAKARIA, A.H.; PLUMSTEAD, P.W.; ROMEROSANCHEZ, H. et al. The effects of oviposition time on egg weight loss during storage and incubation, fertility and hatchability of broiler hatching eggs. Poult. Sci., v.88, p.2712-2717, 2009. 